\title{
Efeito antimicrobiano in vitro do extrato de jabuticaba [Myrciaria cauliflora (Mart.)O.Berg.] sobre Streptococcus da cavidade oral
}

\begin{abstract}
CARVALHO, C.M. ${ }^{1^{*}}$; MACEDO-COSTA, M.R. ${ }^{2}$, PEREIRA, M.S.V. ${ }^{3}$; HIGINO, J.S. ${ }^{4}$; CARVALHO, L.F.P.C. ${ }^{5}$; COSTA, L.J. ${ }^{6}$ Departamento de Odontologia Restauradora, Centro de Ciências da Saúde, Universidade Federal da Paraíba, Campus Universitário, João Pessoa, PB, 58051-900. carine.markus@gmail.com. ²Departamento de Biologia Molecular, Centro de Ciências Exatas e da Natureza, Universidade Federal da Paraíba, Campus Universitário, João Pessoa, PB, 58059-900. mariareginamacedo@yahoo.com.br. ${ }^{3}$ Departamento de Biologia Molecular, Centro de Ciências Exatas e da Natureza, Universidade Federal da Paraíba, Campus Universitário, João Pessoa, PB, 58059-900. svieira@dbm.ufpb.br. ${ }^{4}$ Departamento de Farmácia, Centro de Ciências da Saúde, Universidade Federal de Pernambuco, Recife, PE, 50740-521. Departamento de Clínica e Odontologia Social, Centro de Ciências da Saúde, Universidade Federal da Paraíba, Campus Universitário, João Pessoa, PB, 58051-900. luizfernandood@gmail.com. ${ }^{6}$ Departamento de Clínica e Odontologia Social, Centro de Ciências da Saúde, Universidade Federal da Paraíba, Campus Universitário, João Pessoa, PB, 58051-900. linoj@uol.com.br
\end{abstract}

\begin{abstract}
RESUMO: Este estudo avaliou a ação do extrato etanólico das folhas de Myrciaria cauliflora (Mart.)O.Berg. sobre três culturas de Streptococcus formadoras do biofilme dental. A atividade antimicrobiana foi determinada pelo método de difusão em meio sólido. Os dados obtidos foram satisfatórios para todas as espécies ensaiadas (Streptococcus mutans ATCC 25175, Streptococcus sobrinus ATCC 27609 e Streptococcus sanguis ATCC 10557) gerando halos de inibição quando utilizado o extrato puro e diluições 1:2 e 1:4. Os resultados incentivam a realização de novas pesquisas que viabilizem a produção de compostos com finalidade terapêutica que possam ser utilizados clinicamente na odontologia.
\end{abstract}

Palavras-chave: Myrciaria cauliflora, atividade antimicrobiana, Streptococcus mutans, Streptococcus sobrinus, Streptococcus sanguis

\begin{abstract}
In vitro antimicrobial effect of jabuticaba [Myrciaria cauliflora (Mart.)O.Berg] extract on Streptococcus from the oral cavity. This study evaluated the action of ethanolic extract of Myrciaria cauliflora (Mart.)O.Berg leaves on three Streptococcus cultures from dental plaque. Antimicrobial activity was assessed by agar-well diffusion method. The obtained data were satisfactory for all assayed species (Streptococcus mutans ATCC 25175, Streptococcus sobrinus ATCC 27609 and Streptococcus sanguis ATCC 10557) yielding inhibition halos when the pure extract and 1:2 and 1:4 dilutions were used. These results encourage new studies for the production of therapeutic compounds to be used in clinical dentistry.
\end{abstract}

Key words: Myrciaria cauliflora, antimicrobial activity, Streptococcus mutans, Streptococcus sobrinus, Streptococcus sanguis

\section{INTRODUÇÃO}

A cárie dental é uma doença de etiologia multifatorial relacionada a fatores como dieta, microbiota bucal, hábitos de higiene, características salivares e, constitui-se, juntamente à doença periodontal, nos problemas bucais mais freqüentes na saúde pública do Brasil (Pinto, 2000). Do ponto de vista microbiológico, o aparecimento de lesões da doença está ligado à complexa estrutura do biofilme dental que envolve a participação de vários microrganismos como o Streptococcus mutans ( $S$. mutans), Streptococcus sobrinus (S. sobrinus) e Streptococcus sanguis ( $S$. sanguis,) os quais colonizam a superfície dos elementos dentários pouco tempo após a irrupção dos mesmos na cavidade bucal (Kawashima et al., 2003; Svensater et al., 2003; Lindquist \& Emilson, 2004; Marsh, 2004; Seki et al.,

Recebido para publicação em 30/01/2008

Aceito para publicação em 04/09/2008

Rev. Bras. PI. Med., Botucatu, v.11, n.1, p.79-83, 2009. 
2006).

A aderência das bactérias às superfícies dentárias inicia-se através de uma película adquirida acelular constituída por proteínas e glicoproteínas oriundas da saliva e fluido gengival. Após a colonização inicial de bactérias, ocorre o aumento da quantidade e da diversidade microbiana proporcionando a formação e acúmulo do biofilme dental, fator etiológico determinante da cárie dentária e maioria das doenças bucais. Um dos fatores primordiais ao desenvolvimento do biofilme cariogênico é o acúmulo de estreptococos que leva à produção de ácidos proporcionando queda do $\mathrm{pH}$ e aumento da possibilidade de desmineralização dos tecidos dentais (Murata, 2004). A promoção da higiene bucal, utilizando métodos mecânicos e/ou químicos, reduz ou elimina o biofilme dental prevenindo o aparecimento ou diminuindo a severidade da cárie e doenças periodontais (Fejerskov, 2004).

O estudo de compostos e extratos de produtos naturais tem sido realizado visando a obtenção de agentes antimicrobianos que possibilitem a prevenção de doenças bucais, especialmente as relacionadas ao biofilme dental, com o máximo de efetividade e o mínimo de agressão ao organismo (Botelho et al., 2007). Deste modo, a atividade antimicrobiana de produtos naturais sobre microrganismos, principalmente os do gênero Streptococcus, foram alvo de pesquisas conduzidas por Filoche et al. (2005), Uzel et al. (2005), Melo et al. (2006), Percival et al. (2006), Vasconcelos et al. (2006), Xiao et al. (2006) e Botelho et al. (2007).

A espécie Myrciaria cauliflora conhecida, popularmente, como jabuticaba paulista, jabuticaba assú (Ascheri et al., 2006) ou jabuticaba ponhem (Brunini et al., 2004), é uma planta nativa do Brasil, da Mata Atlântica, que vegeta diversos solos, podendo ser encontrada desde o Pará ao Rio Grande do Sul. Os estudos fitoquímicos da jaboticaba encontrados na literatura são poucos, estando reportada a presença de ácido ascórbico, taninos e glicosídeos cianidínicos e peonidínicos (Reynertson, 2006). Macedo-Costa (2008) observou resultados positivos do extrato do caule de Myrciaria cauliflora Berg.sobre cepas de Lactobacillus caseie Streptococcus mitis.

Este estudo teve como objetivo determinar in vitro a atividade antimicrobiana do extrato hidroalcoólico das folhas de Myrciaria cauliflora sobre culturas de $S$. mutans, $S$. sobrinus e $S$. sanguis, microrganismos formadores do biofilme dental.

\section{MATERIAL E MÉTODO}

Foi estudada a folha da jabuticaba (Myrciaria cauliflora). O material botânico foi adquirido no mercado público de João Pessoa (Paraíba) e identificado botanicamente no Laboratório de
Toxicologia do Departamento de Ciências Farmacêuticas da Universidade Federal de Pernambuco. As folhas foram lavadas com água para separação da matéria-prima a ser utilizada na pesquisa que, em seguida, foi levada à secagem permanecendo, durante uma semana, em estufa a 33ํㅡ para eliminação da umidade e estabilização do conteúdo enzimático. Posteriormente, o material foi retirado da estufa, triturado a pó em moinho elétrico. A extração ocorreu através da solução extratora de álcool metanol (a 80\% v/v) renovado, constantemente, por um período de 24 horas, pelo qual se obteve um concentrado de $500 \mathrm{~mL}$ acondicionado em frasco âmbar, limpo, seco e estocado em câmara fria. A concentração da solução em nível de extrato fluido 1:1 (p/v) foi realizada em rota-vapor (Modelo lka-Werk) a uma temperatura constante de $45^{\circ} \mathrm{C}$.

As linhagens bacterianas de Streptococcus mutans ATCC 25175, Streptococcus sobrinus ATCC 27609 e Streptococcus sanguis ATCC 10557, utilizadas neste estudo, foram obtidas mediante solicitação na Fundação Tropical de Pesquisas e Tecnologia "André Tozello" (Campinas/SP), remetidas em Agar Sangue Inclinado ("slants") e, posteriormente, reativadas no Laboratório de Genética de Microrganismos - Departamento de Biologia Molecular/ CCEN da Universidade Federal da Paraíba.

Para determinação, in vitro, da atividade antimicrobiana em placas e da Concentração Inibitória Mínima (CIM) do extrato, foi utilizado o método de difusão em meio sólido. O experimento foi realizado em duplicata para cada cepa ensaiada, sendo considerada como CIM a menor concentração do extrato capaz de ocasionar inibição completa de crescimento bacteriano. As linhagens bacterianas foram cultivadas em caldo nutritivo (BHI - Brain Heart Infusion - DIFCO) e incubadas a $37^{\circ} \mathrm{C}$, em estufa biológica, sob condições de microaerofilia, pela técnica da chama da vela por 18 a 20 horas. Perfurações de, aproximadamente, $6 \mathrm{~mm}$ de diâmetro foram realizadas no meio de cultura (Agar Mueller Hinton - DIFCO, acrescido de sacarose) onde foram depositados $50 \mu \mathrm{L}$ das soluções do extrato diluído, com diluições variando de $5 \%$ a $0,15 \%$. As placas foram incubadas, em estufa bacteriológica a $37^{\circ} \mathrm{C}$, por um período de 24 horas. Decorrido o período de incubação, os diâmetros dos halos de inibição do desenvolvimento bacteriano foram mensurados, em milímetros, da borda do poço ao início do desenvolvimento.

\section{RESULTADO E DISCUSSÃO}

Os controles mecânico e químico do biofilme dental constituem-se nos principais métodos preventivos empregados contra a cárie dentária e as doenças periodontais. A busca por produtos naturais,

Rev. Bras. Pl. Med., Botucatu, v.11, n.1, p.79-83, 2009. 
que apresentem satisfatória ação antimicrobiana, de forma a inibir os microrganismos cariogênicos e periodontopatogênicos impulsiona a realização de ensaios in vivo e in vitro utilizando extratos de plantas.

$\mathrm{O}$ agente químico utilizado para controle microbiano na cavidade bucal deve ser inócuo aos tecidos bucais, reduzir o biofilme bacteriano e gengivite, inibir a calcificação do biofilme, não favorecer a resistência bacteriana, não manchar os dentes e apresentar substantividade. No entanto, nenhum dos produtos disponíveis comercialmente apresenta todas essas características destacandose a clorexidina como um dos agentes mais utilizados na atualidade (Lindhe, 1999).

Neste estudo, o extrato hidroalcoólico das folhas de Myrciaria cauliflora obteve ação antimicrobiana positiva sobre linhagens de $S$. mutans, $S$. sobrinus e $S$. sanguis, microrganismos aeróbios predominantes no biofilme supragengival (Figura 1). Pode-se observar, na Tabela 1, que a ação antimicrobiana foi homogênea para as linhagens ensaiadas e ainda, que a inibição do crescimento bacteriano diminuiu, conforme ocorreu a redução na concentração do extrato, sendo possível observar a formação de halos de inibição a partir do extrato puro até a sua segunda diluição. Os resultados também aparecem representados pela Figura 2.

Efeitos antimicrobianos efetivos sobre os $S$. mutans também foram encontrados por Filoche et al. (2005), Melo et al. (2006), Percival et al. (2006), Vasconcelos et al. (2006) e Xiao et al. (2006) que estudaram óleos essenciais de canela, extratos da casca do caule de cajueiro, cacau, alecrim-pimenta e própolis, respectivamente. Os $S$. mutans são juntamente aos $S$. sobrinus os microrganismos mais comumente encontrados na microflora bucal e, apesar destes apresentarem menor prevalência, crianças portadoras de ambas as espécies apresentam maior susceptibilidade à cárie dental que aquelas que possuem apenas uma delas (Linquist \& Emilson,

TABELA 1. Concentração Inibitória Mínima, em meio sólido, do extrato hidroalcoólico de Myrciaria cauliflora, sobre linhagens de $S$. mutans, $S$. sobrinus e $S$. sagüis.

\begin{tabular}{|c|c|c|c|c|c|c|c|c|c|c|}
\hline \multirow{3}{*}{ Linhagens Bacterianas } & \multicolumn{10}{|c|}{ Diâmetro dos Halos de Inibição (mm) } \\
\hline & \multicolumn{10}{|c|}{ Concentraçăo do Extrato (mg mL $\left.{ }^{-1}\right)$} \\
\hline & EP & $1: 2$ & 1:4 & $1: 8$ & $1: 16$ & $1: 32$ & $1: 64$ & $1: 128$ & $1: 256$ & 1.512 \\
\hline Streptococcus mutans & 16 & 14 & 12 & 0 & 0 & 0 & 0 & 0 & 0 & 0 \\
\hline Streptococcus sanguis & 16 & 14 & 13 & 0 & 0 & 0 & 0 & 0 & 0 & 0 \\
\hline Streptococcus & i. & $\cdots$ & - & - & - & - & - & - & 0 & 0 \\
\hline
\end{tabular}

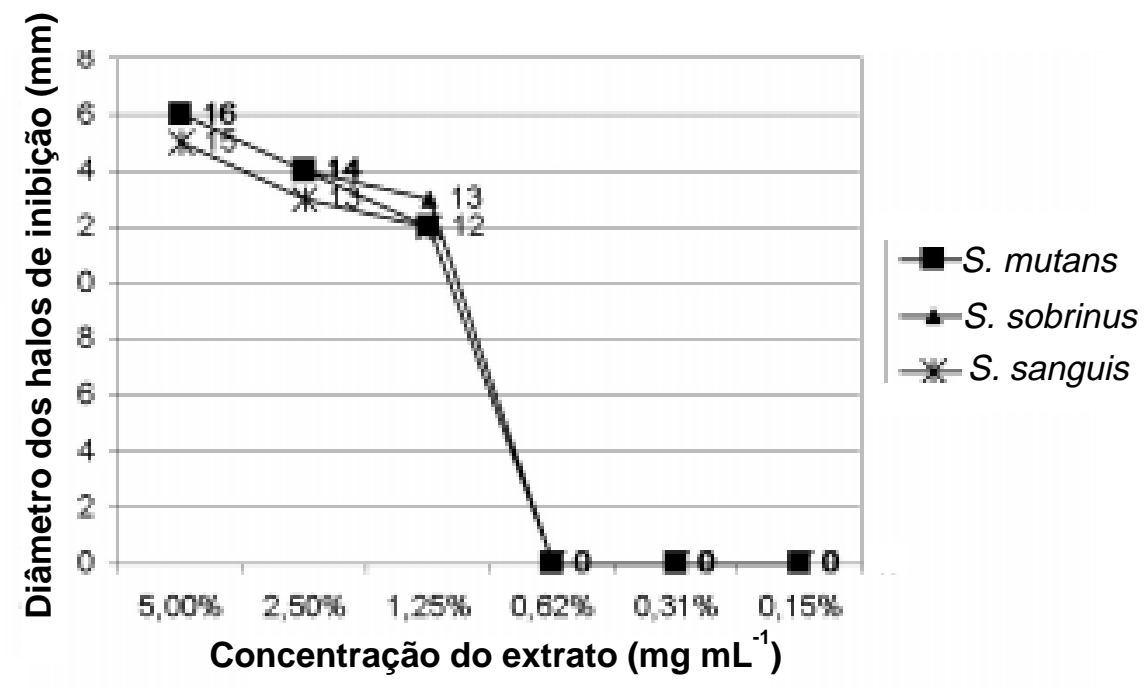

FIGURA 1. Representação gráfica da Concentração Inibitória Mínima (CIM) do extrato de folhas de jabuticabeira sobre linhagens de $S$. mutans, S. sobrinus e S. sanguis. 


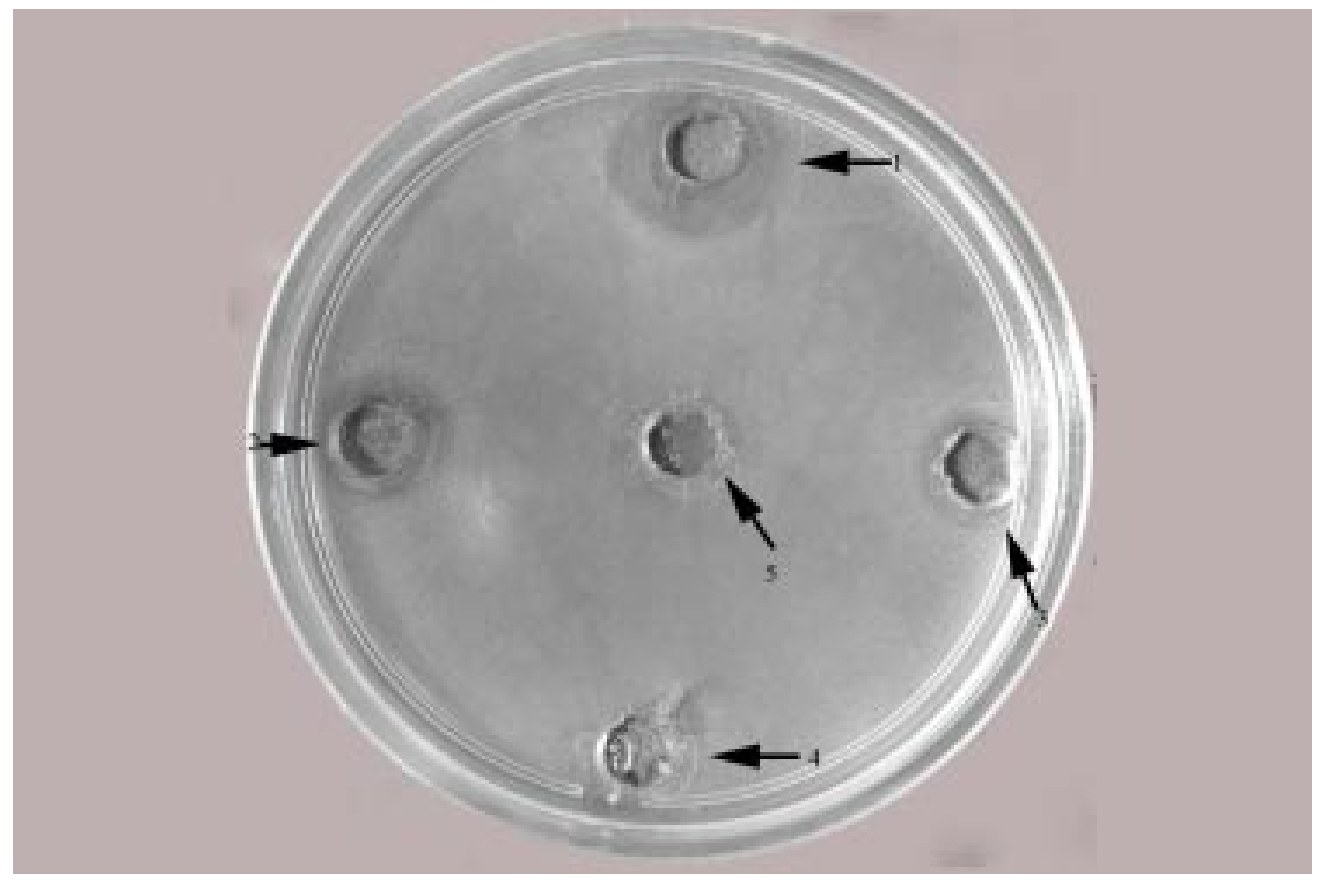

FIGURA 2. Atividade antimicrobiana do extrato hidroalcoólico das folhas de Myrciaria cauliflora sobre o crescimento de Streptococcus. mutans nas concentrações de (1) extrato puro; (2) diluição 1:2; (3) diluição 1:4; (4) diluição 1:8; (5) diluição 1:16.

2003). Resultados satisfatórios sobre os S. mutans e $S$. sobrinus também foram encontrados por Gebara et al. (1996) com a utilização de cacau, própolis e tomilho.

De acordo com Percival et al. (2006), o prétratamento das superfícies dentárias com os fenóis pentâmeros do cacau, produz o efeito de reduzir a formação do biofilme dental por $S$. mutans, efeito não observado sobre o $S$. sanguis. No entanto, quando estudada a atividade antimicrobiana dos fenóis do cacau, observou-se a inibição do crescimento apenas de $S$. sanguis. Efeito positivo sobre a inibição de ambas as espécies foi obtido com a utilização do extrato do caule do Anacardium occidentale por Melo et al. (2006).

Neste estudo, o extrato das folhas de Myrciaria cauliflora apresentou bom efeito inibitório sobre o crescimento de todas as espécies bacterianas estudadas ( $S$. mutans, $S$. sobrinus e $S$. sanguis) suscitando assim a possibilidade da sua incorporação a agentes antibiofilme como colutórios e dentifrícios.

Dado o exposto, pode-se concluir que o extrato das folhas da Myrciaria cauliflora apresenta potencial atividade antimicrobiana sobre Streptococcus mutans, Streptococcus sobrinus e Streptococcus sagüis. Este estudo serve de subsídio a futuros experimentos que visem elucidar as substâncias ativas deste extrato bem como seu mecanismo de ação, toxicidade e atividade antimicrobiana sobre outros microrganismos. Abusca por agentes antimicrobianos com aplicabilidade terapêutica e economicamente viáveis torna-se um evento importante na promoção da saúde bucal da população.

\section{REFERÊNCIA}

ASCHERI, D.P.M.; ASCHERI, J.L.M; CARVALHO, C.W.P. Caracterização da farinha de bagaço de jabuticaba e propriedades funcionais dos extrusados. Ciência e Tecnologia Alimentar Campinas, v.26, n.4, p.1-9, 2006. BOTELHO, M.A. et al. Antimicrobial activity of the essencial oil from Lippia sidoides, carvacrol and thymol against other pathogens. Brazilian Journal of Medical and Biological Research, v.40, p.349-56, 2007.

BRUNINI, M.A. et al. Influencia de embalagens e temperatura no armazenamento de jabuticabas (Myrciaria jabuticaba Berg) cv "sabará". Ciência e Tecnologia Alimentar Campinas, v.24, n.3, p.378-83, 2004.

FEJERSKOV, O. Changing paradigms in concepts on dental caries: consequences for oral health care. Caries Research, v.38, p.182-91, 2004

FILOCHE, S.K.; SOMA, K.; SISSONS, C.H. Antimicrobial effects of essential oils in combination with chlorhexidine digluconate. Oral Microbiology Immunology, v.20, p.2215, 2005.

GEBARA, E.C.E.; ZARDETTO, C.G.D.C.; MAYER, M.P.A Estudo in vitro da ação antimicrobiana de substâncias naturais sobre $S$. mutans e $S$. sobrinus. Revista de Odontologia da Universidade de São Paulo, v.10, p.2516, 1996.

KAWASHIMA, M. et al. Real time interaction of oral 
streptococci with salivary components. Oral Microbiology Immunology, v.18, p.220-5, 2003.

LINDQUIST, B.; EMILSON, C.G. Colonization of Streptococcus mutans and Streptococcus sobrinus Genotypes and Caries Development in Children to Mothers Harboring Both Species. Caries Research, v.38, p.95-103, 2004.

LINDHE, J. Tratado de periodontia clínica e implantodontia oral. 3.ed. Rio de Janeiro: Guanabara Koogan, 1999. 720p.

MACEDO-COSTA, M.R. Atividade antimicrobiana e antiaderente de Mimosa tenuiflora (Willd) Poir e Myrciaria cauliflora Berg sobre bactérias do biofilme dental. 2008. 72p. Monografia (Graduação em Odontologia) Universidade Federal da Paraíba, João Pessoa.

MARSH, P.D. Dental plaque as a microbial film. Caries Research, v.38, p.204-11, 2004.

MELO, A.F.M. et al. Atividade antimicrobiana in vitro do extrato de Anacardium occidentale $\mathrm{L}$. sobre espécies de Streptococcus. Revista Brasileira de Farmacognosia, v.16, n.2, p.202-5, 2006.

MURATA, R.M. Avaliação in vitro do efeito do kaempferol e tt-farnesol sobre o biofilme dental-inibição e viabilidade bacteriana. 2004. 38p. Dissertação (Mestrado - Área de Concentração em Farmacologia, Anestesiologia e Terapêutica) - Faculdade de Odontologia de Piracicaba, Universidade Estadual de Campinas, Piracicaba.

PERCIVAL, R.S. et al. The effect of cocoa polyphenols on the growth, metabolism and biophilm formation by
Streptococcus mutans and Streptococcus sanguinis European Journal of Oral Scince, v.114, p.343-8, 2006. PINTO, V.G.P. Saúde bucal coletiva. 4.ed. São Paulo: Livraria e Editora Santos, 2000. 202p.

REYNERTSON, K.A. et al. Bioactive depsides and anthocyanins from jaboticaba (Myrciaria cauliflora). Journal of Natural Products, v.69, p.1228-30, 2006.

SEKI, M. et al. Effect of mixed mutans streptococci colonization on caries development. Oral Microbiology Immunology, v.21, p.47-52, 2006.

SILVEIRA, F.T. et al. 2006. Caracterização citogenética em duas espécies do gênero Myrciaria. Revista de Biologia e Ciências da Terra, v.6, n.2, p.327-33, 2006. SVENSATER, G. et al. The acid-tolerant microbiota associated with plaque from initial caries and healthy tooth surfaces. Caries Research, v.37, p.395-403, 2003. VASCONCELOS, L.C.S. et al. Minimum inhibitory concentration of adherence of Punica granatum L. (pomegranate) gel against $S$. mutans, $S$. mitis and $C$. albicans. Brazilian Dental Journal, v.17, n.3, p.2237, 2006.

UZEL, A. et al. Chemical compositions and antimicrobial activities of four different Anatolian propolis samples. Microbiological Research, v.160, p.189-95, 2005.

$\mathrm{XIAO}$, J. et al. Effects of Nidus vespae extract on the growth and acidogenicity of oral microorganisms. Archives of Oral Biology, v.51, p.804-13, 2006. 